\title{
ECO FASHION: UMA NOVA TENDÊNCIA DE MODA1
}

Neide Köhler Schulte ${ }^{2}$

RESUMO: Este artigo apresenta os resultados da pesquisa Eco Fashion: consolidação de uma tendência ecológica na moda no período de 2005 a 2008. A pesquisa teve como objetivo identificar requisitos para consolidar uma tendência ecológica para Moda. Serviu de suporte teórico para o Programa de Extensão EcoModa que desenvolve atividades, com a comunidade da Grande Florianópolis, que relacionam moda e meio ambiente. Os resultados são apresentados e divulgadas em outras cidades do estado de Santa Catarina, em outros estados e no exterior, na forma de desfiles, palestras e exposições.

PALAVRAS-CHAVE: Moda; Meio ambiente; Tendência ecológica; Programa de extensão.

\section{INTRODUÇÃO}

A pesquisa 'Eco Fashion: consolidação de uma tendência ecológica na moda' teve como objetivo identificar requisitos para consolidar uma tendência ecológica para moda, e novas propostas de moda que trabalham com uma perspectiva ecológica, procurando estabelecer um consumo consciente.

Este artigo apresenta inicialmente o conceito de sustentabilidade ambiental e sua implicação para o desenvolvimento humano, partindo do princípio de que é imperativa a necessidade de considerar os impactos ambientais causados pelas atividades humanas.

A partir do conceito de sustentabilidade ambiental são apresentadas propostas de estilistas, marcas e ações com a comunidade para formação de uma consciência para novas possibilidades que desenvolvem produtos de moda que agregam o conceito de ‘ecologicamente correto'. Na UDESC ${ }^{3}$ é desenvolvido o Programa de Extensão EcoModa, apresenta-se as principais atividades desenvolvidas na comunidade da Grande Florianópolis, no período de 2005 à 2008, e finaliza-se com as considerações sobre as atividades desenvolvidas na pesquisa articulada com a extensão.

\section{ECO FASHION: CONCEITO DE SUSTENTABILIDADE AMBIENTAL}

1 Pesquisa Eco Fashion: consolidação de uma tendência ecológica na moda

2 Neide Köhler Schulte - Departamento de Moda

3 Universidade do Estado de Santa Catarina 
O conceito de sustentabilidade foi inventado a mais de trinta anos para sugerir que era possível conseguir o crescimento econômico e a industrialização sem destruir o meio ambiente ${ }^{4}$.

O desenvolvimento sustentável é aquele que atende às necessidades do presente, sem comprometer a possibilidade das gerações futuras de atenderem às suas próprias necessidades $^{5}$. Esta definição trata de dois pontos fundamentais: o problema da degradação ambiental, que geralmente acompanha o crescimento econômico, e a necessidade que esse crescimento contribua para reduzir a pobreza.

O desenvolvimento sustentável implica em três grandes desafios para a humanidade. Primeiro: garantir a disponibilidade de recursos naturais transformados em bens e serviços necessários no cotidiano. Segundo: não lançar sobre a biosfera do planeta substâncias tóxicas, resíduos e poluição, decorrentes da produção e uso de bens e serviços em quantidades e velocidades superiores á capacidade de auto-depuração da natureza. Terceiro: reduzir a pobreza mundialmente ${ }^{6}$.

Apesar de mais de três décadas de preocupação com a sustentabilidade, continua a redução dos recursos naturais em quase todo planeta, assim como os problemas da pobreza. $\mathrm{Ou}$ seja, os desafios da humanidade para atingir um desenvolvimento sustentável ainda parecem distantes da superação.

Qual seria a razão para um processo tão lento da assimilação de uma mudança da relação do homem com o meio ambiente, de respeito e de valorização, tão necessária para o futuro da humanidade, seria a visão antropocêntrica?

A definição de sustentabilidade ambiental é antropocentrista: futuras gerações de pessoas possuem tanto direito a viver fisicamente seguras e saudáveis como as pessoas das presentes gerações. Cada ser humano está sob uma obrigação de não permitir que o meio-ambiente natural se deteriore a ponto que seja comprometida a sobrevivência e bem-estar dos futuros habitantes humanos da terra. Também possui um dever de conservar os recursos naturais para que as futuras gerações possam usufruir dos muitos benefícios derivados desses recursos. A responsabilidade presente de proteger espécies selvagens ameaçadas está ligada aos valores humanos. Além do mais, algumas vezes é argumentado que a variedade de espécies de plantas e animais é necessária para desenvolver novas maneiras de proteger os humanos de doenças, a se livrar de bactérias perigosas, de aprender como controlar certos insetos e outras 'pes-

4 Conferência das Nações Unidas sobre Meio Ambiente, em Estocolmo, em 1972. LEMOS e BARROS 2007, pg 19.

5 Definição da Comissão Mundial de Meio Ambiente e Desenvolvimento das Nações Unidas, publicado em 1987. LEMOS e BARROS 2007, pg 9.

6 LEMOS e BARROS 2007, pg 9 - 11. 
tes' e produzir novas fontes de comida por meio da engenharia genética. Os humanos também possuem uma obrigação de preservar a beleza da natureza selvagem para que as futuras gerações possam ter tanta oportunidade de experimentar e apreciar essa beleza, como presente. Seria injusto destruir as maravilhas naturais do mundo e que deixar apenas lixo para que os outros contemplem. Além do mais, um sistema inteiro de padrões e regras governando a conduta no presente em relação ao ambiente natural da terra pode ser formada apenas a partir dos interesses e necessidades humanos ${ }^{7}$.

A partir do ponto de vista da teoria biocêntrica da ética ambiental, por outro lado, as obrigações para a natureza não se sustentam pelas obrigações com os humanos. A ética ambiental não é uma subdivisão da ética humana. Embora muitas das ações estejam corretas de acordo com uma teoria biocêntrica, há o que torna essas ações corretas no caso de um jogo completamente diferente de considerações. Os princípios morais envolvidos são fundamentalmente separados e distintos. Os dois pontos de vista, um sistema ético antropocêntrico ou biocêntrico, nem sempre possuem os mesmos resultados. Isso implica numa diferença prática na forma como os humanos tratam o ambiente natural. Quando um ponto de vista biocêntrico é tomado, as obrigações e responsabilidades a respeito dos animais selvagens e plantas da Terra são vistos para levantar certas relações morais entre os humanos e o mundo natural. O mundo natural não é simples como um objeto a ser explorado pelos humanos, assim como também não são criaturas que podem ser utilizadas como nada mais que recursos de uso e consumo ${ }^{8}$.

É comum a crença de que a existência do ser humano é mais valiosa do que a existência de um animal ou planta. Humanos vivem em um plano superior, possuem uma dignidade e um valor que estão ausentes em outras formas de vida, algo mais importante, algo de maior valor é perdido para o mundo quando morre um ser humano que não é perdido para o mundo quando um leão, uma serpente, ou uma árvore morre. Esta idéia é tão profundamente enraizada em várias culturas, que é difícil pensar de forma clara e crítica sobre o assunto. Para muitas pessoas, parece perfeitamente evidente que o bem-estar dos seres humanos tem maior valor e, consequentemente, deve ser dada maior peso nas suas deliberações morais, além do bem-estar dos animais e plantas. No entanto, quando se busca descobrir razões objetivas que justifiquem esta crença, frequentemente, se confronta com uma metafísica obscura e acrítica.

Para que seja possível uma sustentabilidade ambiental genuína, é necessária uma visão biocêntrica da natureza. Enquanto se tratar a natureza apenas como um valor utilitário para os 
humanos, sem considerar seu valor inerente, não haverá sustentabilidade ambiental. Se os princípios da sustentabilidade ambiental devem estar incorporados ao desenvolvimento humano, é preciso estabelecer um conceito mais sólido quanto ao que é ambientalmente sustentável de fato.

A visão antropocêntrica não parece adequada no século XXI, e nunca foi. Os estudos sobre uma ética ambiental biocêntrica indicam que esta visão de mundo, centrada na superioridade humana, é responsável pela degradação do ambiente natural do planeta terra, ou seja, pela grave crise ambiental que poderá limitar a existência humana, nesta e nas próximas gerações.

Diante deste contexto, do desafio de adequar o desenvolvimento econômico a preservação do meio ambiente e minimização da pobreza, da visão antropocêntrica que dirige as ações humanas e dificulta o respeito e a consideração pelas demais formas de vida no planeta, o que poderá impulsionar as mudanças necessárias para o desenvolvimento sustentável?

Para Kazazian, a natureza não tem dogma. Entender as relações dinâmicas que nela se produzem é a primeira etapa a superar para obter respostas à complexidade das dificuldades encontradas. Nesse campo de reflexão, quatro grandes dimensões interligadas podem ser consideradas. A primeira é a noção de 'interdependência'. Cada elemento - ou cada sistema existe pela soma de suas relações com os outros, e em uma geometria temporal - ou uma duração - que lhe é própria: 'o tempo', a segunda dimensão. Dela aparece a idéia de 'ciclo'. Aparecer, desaparecer, mudar de estado para alimentar outros ciclos, é assim que a vida se compõe e se recompõe, infinitamente. Por fim, os elementos em conjunto - ou os sistemas se desenvolvem na medida em que recebem energia, em um perpétuo fenômeno de 'auto-regulação"9.

Além de entender a dinâmica da natureza é preciso desejar o desenvolvimento sustentável, a partir disso, com a criatividade humana é possível idealizar e conceber novos produtos ou serviços mais adequados, diante da crise ambiental.

Uma vez desejado o desenvolvimento sustentável é preciso entender que praticar a sustentabilidade ambiental significa cuidar de todas as coisas, das menores até o planeta inteiro e vice-versa.

Portanto, para a transição à sustentabilidade, são apontados dois caminhos:

Por caminhos traumáticos, uma transição forçada por efeitos catastróficos, que de fato obrigam a uma reorganização do sistema, a mais indolores, uma transição por escolha, isto é, como efeitos de mudanças culturais, econômicas e políticas voluntárias que reorientem as atividades de produção e consumo ${ }^{\mathbf{1 0}}$.

9 KAZAZIAN, 2005, pg 28.

10 MANZINI, E; VEZZOLI, C, 2005, pg. 45.

DAPesquisa, Florianópolis, v.3 n.5, p.559-566, 2008. 
O segundo caminho indicado, a transição por escolha, é o que está se tentando a mais de trinta anos, desde a Conferência das Nações Unidas sobre Meio Ambiente, em Estocolmo, em 1972. Ao que parece, o que tem acelerado a transição tem sido alguns efeitos catastróficos decorrentes das mudanças climáticas que tem ocasionado grandes enchentes, secas, tornados, entre outros. Segundo Roberts, estes efeitos também vêm comprometendo a produção de alimentos e de outras matérias primas naturais utilizados pelas indústrias.

\begin{abstract}
As mudanças climáticas vão dificultar o aumento na produção de comida e acentuar a escassez de água. A alteração do clima também será um desafio para que grandes exportadores, como os Estados Unidos e o Canadá, consigam elevar sua produção. Os desafios são complexos e as respostas para eles também. Será preciso reduzir o uso de energia e de água na agricultura, ao mesmo tempo que se elevam a eficiência e a produtividade. Porém, isso não será o bastante. Seremos obrigados a comer $\operatorname{menos}^{11}$.
\end{abstract}

A redução de consumo tem sido indicada por diversos pesquisadores e teóricos, inclusive de comida. Depois de um século de consumo numa escala crescente, em que várias gerações passaram a associar o aumento de consumo ao aumento do bem-estar, o processo inverso parece mais difícil.

E quando entra em questão a moda ${ }^{12}$, a dificuldade parece se acentuar. Isto porque a moda se relaciona com o novo, com o efêmero, com mudanças cada vez mais rápidas. Com isso, há a busca frenética pela novidade e o aumento de consumo. Este sistema da moda tem grandes conseqüências ambientais que foram ignoradas durante muito tempo.

É complexa a interação entre o homem, os objetos e a natureza. É o que Capra define como uma teia interconexa de relações ${ }^{13}$ quando se refere ao modo como deve der vista a natureza. Tudo está interligado. Se as tendências de moda, por sua vez, indicarem o uso de materiais orgânicos, reciclados, reaproveitados, menos poluentes, o não uso de peles de animais, entre outros, haverá uma contribuição significativa para reorientar a produção, os serviços e o consumo de moda.

Está tendência ecológica para a moda não é apenas uma suposição. Ela já lançada e pode ser observada nas coleções de grandes estilistas internacionais.

A estilista inglesa Vivienne Westwood, considerada a mãe do punk e uma das designers mais influentes do século 20, fez um apelo para que as pessoas consumam menos e façam melhor suas escolhas de compra. A estilista de 66 anos, que lançou em São Paulo, em

11 ROBERTS, Paul. The End of Food. Entrevista para revista Época em 16/06/2008, disponível em: http://www.linearclipping.com.br/

12 O termo Moda neste texto se refere ao produto de vestuário.

13 CAPRA, 1996, 
janeiro de 2008 durante a SPFW ${ }^{14}$, duas sandálias de plástico em parceria com uma empresa brasileira, rebate as críticas de quem a chama de 'hipócrita' por seu discurso anticonsumista, já que ela mesma produz coleções veneradas pelo mundo fashion. Segundo Westwood, hipócritas são as pessoas que têm dinheiro e se vestem como pobres. Eles deveriam comprar roupas bacanas, mas não muitas. Para ela, as pessoas devem discriminar mais, não ser engolidas por tudo o que se propõe. São privilegiadas porque podem escolher as roupas, mas devem escolhê-las melhor. Ela afirmou ainda que gostaria de produzir menos. "Eu realmente estou cansada de fazer tanto. Prefiro muito, muito fazer menos e fazê-lo muito bem. Só preciso descobrir como ${ }^{15}$."

Descobrir como fazer uma moda 'melhor', mais adequada ao contexto do desenvolvimento sustentável, tem sido o grande desafio da moda nos dois últimos anos. É uma tendência recente, ou melhor, já pode ser considerado um paradigma, se é que se pode aplicar este termo para a moda. Antes disso, a natureza aparecia nas tendências de moda apenas como tema para as cores, texturas, ou materiais.

\section{SUSTENTABILIDADE AMBIENTAL NA PRÁTICA: PROGRAMA ECOMODA}

O Programa de Extensão EcoModa/UDESC teve início em agosto de 2005, sob a coordenação dos professores Neide Köhler Schulte e Lucas da Rosa. Surgiu a partir do projeto de extensão 'Desenvolvimento de coleção para o $1^{\circ}$ Veg Fashion', que aconteceu em 2004, para atender a um convite feito por Marly Winckler, presidente da SVB - Sociedade Vegetariana Brasileira - organizadora $36^{\circ}$ Congresso Mundial de Vegetarianismo ${ }^{16}$, para participar do evento com um desfile. O evento foi realizado em Florianópolis no Hotel Resort Costão do Santinho, no período de 08 a 12 de novembro de 2004. O tema proposto para o desfile foi 'moda sem crueldade', todas as peças confeccionadas não tinham nenhuma matéria prima de origem animal, utilizou-se também a reciclagem, o reaproveitamento e materiais com menor impacto ambiental, como o algodão orgânico.

O evento teve projeção internacional, pois o Congresso Mundial de Vegetarianismo reúne pessoas de diversos países para discutir questões relativas ao vegetarianismo: alimentação, consumo consciente, preservação ambiental, filosofia, entre outros.

A participação no evento estimulou o estudo e aprofundamento da temática Moda \& Meio Ambiente dando origem a esta pesquisa e ao Programa EcoModa.

14 São Paulo Fashion Week, janeiro de 2008

15 http://oglobo.globo.com/cultura/mat/ Acesso em: 17/01/2008

16 Congresso Mundial de Vegetarianismo acontece a cada dois anos em um país diferente, em 2004 no Brasil, em 2006 na Índia e em 2008 na Alemanha. 
Partindo da problemática moda e meio ambiente, que envolve uma questão sócioambiental, se criou o Programa de Extensão EcoModa. O objetivo é disseminar o conceito de sustentabilidade ambiental promovendo a interação entre os acadêmicos e a comunidade na busca por soluções em relação à questão sócio-ambiental e a adequação dos produtos ligados ao universo da moda para um contexto de menor impacto ambiental.

O Programa EcoModa é constituído por projetos, eventos, cursos e outras atividades como palestras, exposições, participação em programas de televisão, rádio, entre outros. A maioria das ações acontece em Florianópolis, mas participa-se de desfiles e palestras em outros estados e outros países.

\section{CONSIDERAÇÕES FINAIS}

Desde o início das atividades do Programa EcoModa e da pesquisa Eco Fashion, os desafios identificados têm profunda relação com os desafios para a sustentabilidade ambiental. As questões ambientais estão interligadas com as questões sociais, e ambas, durante muito tempo, foram pouco consideradas diante da importância dada ao crescimento econômico. O cerne do pensamento da sustentabilidade transformou-se em três dimensões: a ambiental, a social e a econômica. Sendo que não pode haver hierarquia entre estas dimensões na busca pela sustentabilidade ambiental.

O objetivo de disseminar o conceito de sustentabilidade ambiental através da moda tem sido atingido a partir das ações realizadas pelo Programa EcoModa. A interação entre os acadêmicos e a comunidade aconteceu durante os cursos, palestras e demais atividades. Foram indicadas algumas soluções para a questão sócio-ambiental como a capacitação de jovens de comunidades em risco social, através de cursos e oficinas com atividades ligadas a moda e, a adequação de produtos de moda para um contexto de menor impacto ambiental, desenvolvidos a partir da reciclagem de materiais, customização, recuperação de roupas, entre outros. Em relação à difusão da proposta do Programa EcoModa no ambiente externo da universidade, observou-se que a extensão universitária é um ótimo meio para alcançar resultados relevantes para a questão sócio-ambiental.

Considera-se que, diante do que foi exposto, o desenvolvimento sustentável somente poderá acontecer se houverem mudanças de valores, se a visão antropocêntrica for substituída por uma visão biocêntrica em relação à natureza, considerando-se o valor de todas as vidas imparcialmente, sem especismo, ou qualquer escala de valor. 
A partir do Programa EcoModa e da pesquisa Eco Fashion, a temática moda e sustentabilidade ambiental, tornou-se objeto de pesquisa para uma tese de doutorado que está em andamento.

\section{REFERÊNCIAS}

CAPRA, Fritjof. A teia da vida: uma nova compreensão científica dos sistemas vivos. São Paulo: Coltrix, 1996.

LEMOS, Haroldo M. e BARROS, Ricardo L.P. O desenvolvimento sustentável na prática.

Rio de Janeiro: Comitê Brasileiro das Nações Unidas para o Meio Ambiente, 2007.

KAZAZIAN, Thierry. Haverá a idade das coisas leves: design e desenvolvimento sustentável. São Paulo: Ed. SENAC, 2005. 194 p.

MANZINI, E; VEZZOLI, C. O desenvolvimento de produtos sustentáveis. Os requisitos ambientais dos produtos industriais. São Paulo: Editora da Universidade de São Paulo, 2005. ROBERTS, Paul. The End of Food. 2008. Entrevista para revista Época, disponível em: http://www.linearclipping.com.br/, acesso em 16/06/2008.

TAYLOR, Paul W. Respect for Nature: a theory of environmental ethics. 2. impress with corrections. New Jersey, Princeton: Princeton University Press, 1987

http://oglobo.globo.com/cultura/mat/ Acesso em: 17/01/2008 